\title{
A NEW PRIMITIVE HELICOPSYCHE FROM MADAGASCAR (TRICHOPTERA: HELICOPSYCHIDAE), WITH PHYLOGENETIC ANALYSIS \\ OF AFROTROPICAL SPECIES
}

\begin{abstract}
Johanson, K. A., 2002. A new primitive Helicopsyche from Madagascar (Trichoptera: Helicopsychidae), with phylogenetic analysis of Afrotropical species. - Tijdschrift voor Entomologie 145: 9-17, fig. 1-11, tables 1-3. [ISSN 0040-7496]. Published 1 June 2002.

A new species of the subgenus Petrotrichia Ulmer, 1910 within the genus Helicopsyche von Siebold, 1856 (Trichoptera), Helicopsyche anomana sp.n. is described. A cladistic analysis was executed to establish its phylogenetical relationship to other Petrotrichia species. The results of the analysis shows that the species is the sister species to Helicopsyche giboni Johanson, 1997, and together they form a basal clade within the Afrotropical Helicopsyche and also within the Helicopsychidae.

Correspondence: K. A. Johanson, Swedish Museum of Natural History, Box 50007, SE-104 05 Stockholm, Sweden. Email: kjell.arne.johanson@nrm.se

Key words. - Helicopsyche anomana sp. n.; Helicopsychidae; Trichoptera; phylogeny; Madagascar.
\end{abstract}

With the description of Helicopsyche palpalis (Ulmer, 1910) from Mahé, Seychelles, Ulmer described the first Helicopsyche von Siebold, 1856 from the Afrotropical region. It was originally described within a new hydroptilid genus Petrotrichia Ulmer, 1910, but was synonymized with Helicopsyche by Marlier \& Malicky (1979). The taxon name Petrotrichia Ulmer, 1910 was maintained by Johanson (1998) as a valid monophyletic subgenus taxon for all Afrotropical $\mathrm{He}$ licopsyche by Johanson (1998). The phylogenetic relationship of the ten East African Petrotrichia was outlined by Johanson \& Willassen (1997) without including the two Madagascan species and the Seychellean H. kantilali Marlier \& Malicky, 1979. They concluded that the East African species are monophyletic. In a cladistic analysis, Johanson (1998) argued that the Petrotrichia forms a basal clade within the genus Helicopsyche. With $H$. anomana sp. n. described herein, the subgenus Petrotrichia now comprises 14 species, of which anomana and giboni Johanson, 1997 are known from Madagascar; H. palpalis (Ulmer, 1910) and H. kantilali from the Seychelles; and all the remaining ten species $(H$. barbata Johanson, 1993, H. pedunculata Johanson, 1993, H. ulugurensis Johanson, 1993, H. usambarensis Johanson, 1993, H. annae Johanson, 1993, H. tanzanica Johanson, 1993, H. stoltzei Johanson, 1993, H. jacque- mart Johanson, 1993, H. bifida Johanson, 1993, and H. marlieri Jaquemart, 1957) are all restricted to Tanzania and eastern Zaire.

The Madagascan Helicopsyche fauna was recently unknown until Johanson (1997) described H. giboni. A second species was kindly sent by Dr. F. M. Gibon and is herein described.

The present understanding of the Madagascan $\mathrm{He}$ licopsyche fauna is that it is poor in species compared to the East African mountains of the Eastern Arc. But both the low number of species and sites where specimens are collected indicates that the island is also poorly known, and that extensive collecting activity will probably lead to the discovery of more species.

\section{METHODS}

The morphological terminology follows Johanson (1998). The holotype is deposited at the Swedish Museum of Natural History, Stockholm, Sweden.

\section{Helicopsyche (Petrotrichia) anomana sp.n.}

Type material. - Holotype $q$ : Madagascar: Rianila Basin, Sahatandra River, at Ambod irina, 48 20'28'E, $19^{\circ} 01^{\prime} 32^{\prime \prime}$ (LRSAE coll.) [no date given]. 

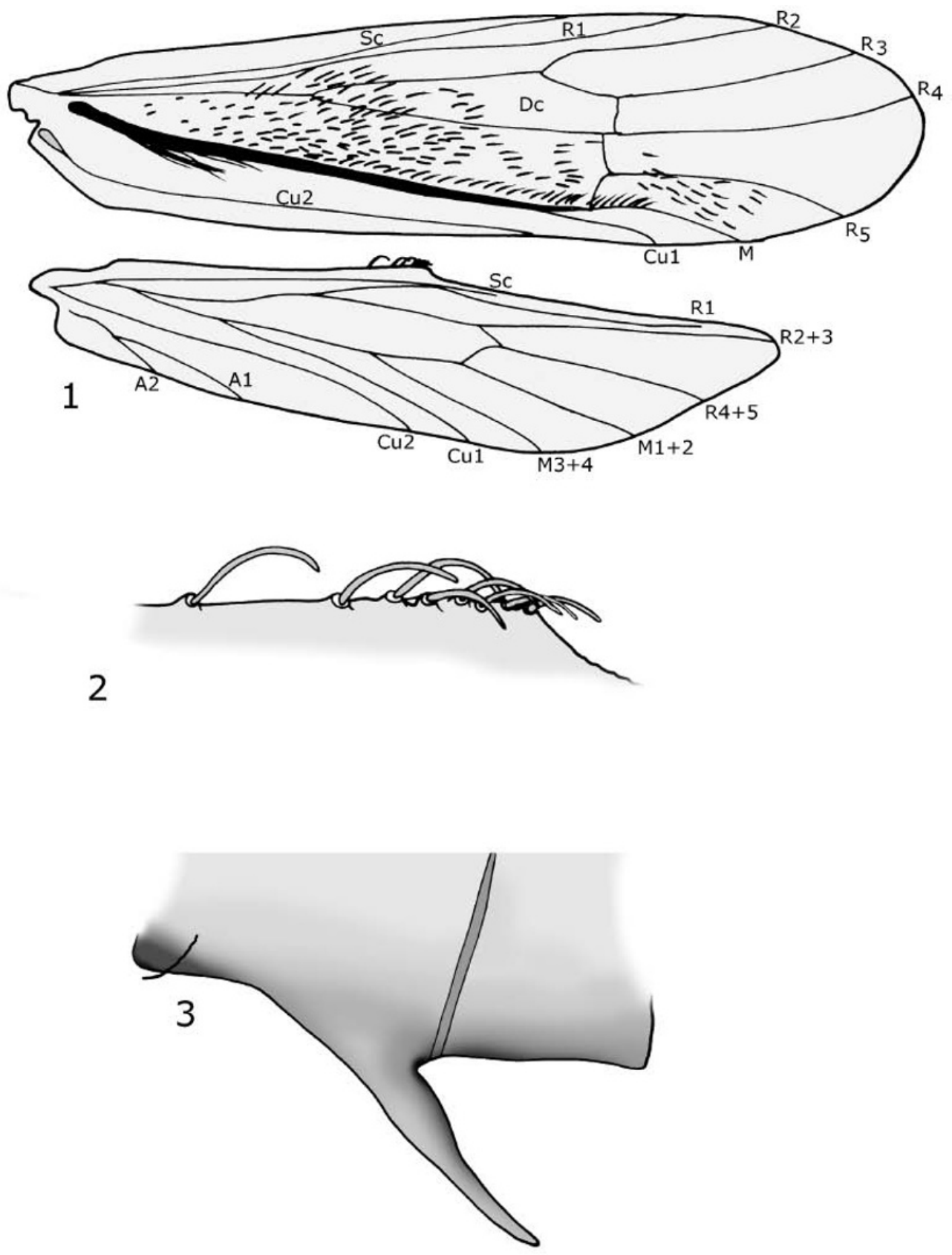

Figs. 1-3. Helicopsyche anomana sp.n., male holotype. - 1, Right wings; 2, hindwing hamuli, highly magnified; 3, VIth sternite, lateral view. 

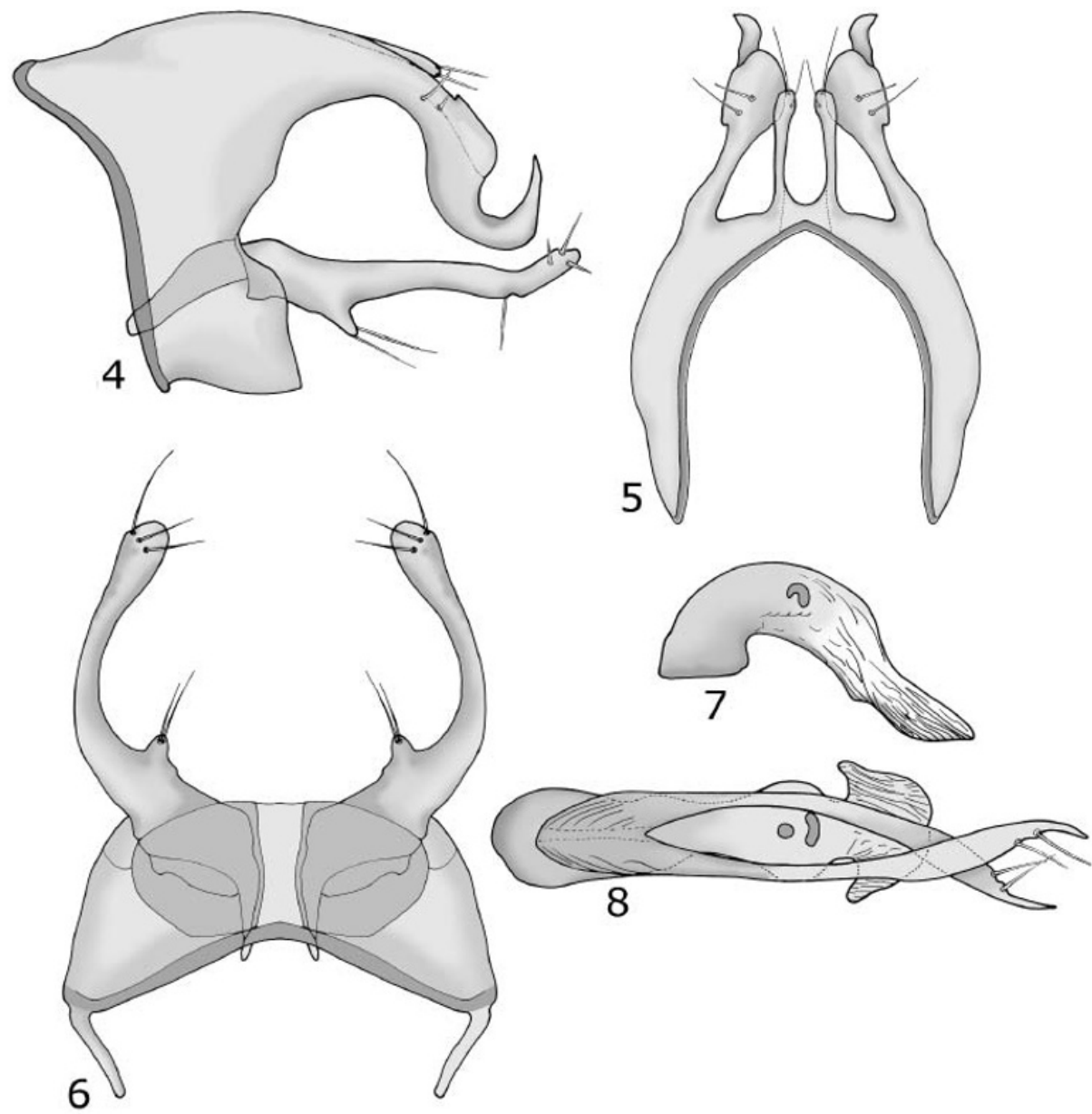

Figs. 4-8. Helicopsyche anomana sp.n., male holotype. - 4, Genitalia, lateral view; 5, genitalia, dorsal view; 6, genitalia, ventral view; 7, phallus, lateral view; 8, phallus and phallic processes, dorsal view.

\section{Diagnostic characters}

The male is characterized by having rounded fore wing apex; no abdominal reticulation; anteriorly pointing dorsal part of segment IX; distally hookshaped tergum X; superior appendages which originate dorsally; slender and distally dorsally bent, simple, gonocoxites; and very long dorsal processes on phallus. $H$. anomana can be separated from its sister species, $H$. giboni, by having forewing with $\mathrm{R}_{5}$ originating proximally to crossvein $\mathrm{R}_{3}-\mathrm{R}_{4}$; in $H$. giboni $\mathrm{R}_{5}$ originates on line with this crossvein; anomana has shorter hamuli row; and anomana has two phallic processes present, while giboni has four phallic processes. H. anomana is slightly larger than giboni.

\section{Etymology}

The name anomana is a paraphrase of the Latin $a b$ normis, abnormal, and referring to the odd genitalic morphology.

\section{Description}

Male (holotype). - Head: maxillary palp with 2 equally long joints; cephalic warts rounded, slightly elevated; postantennal warts rounded, flat; eyes with interommatidial setae; vertex dorsally and anteriorly rounded. Thorax: pronotum and mesoscutum each with one pair setal warts; spurs 2, 2, 4; fore leg posterior spur shorter than anterior spur. Wings (figs. 1, 2): Fore wing $4.1 \mathrm{~mm}$; Dc long, about $1 / 3 \mathrm{x}$ wing length; forks 1 and 2 present; fork 1 originates from distal $1 / 4$ 


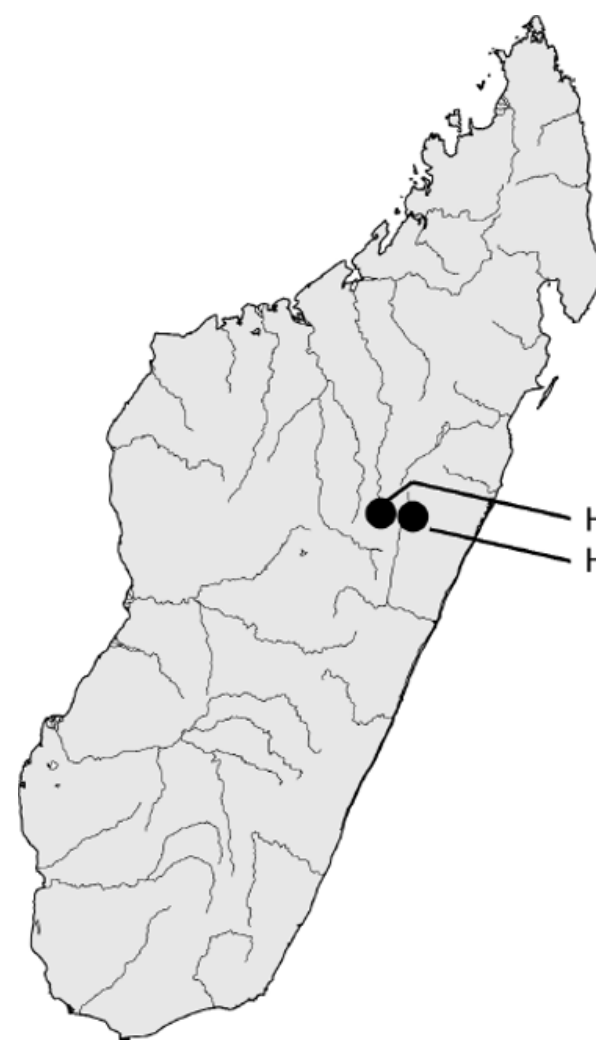

Fig. 9.

Distribution of Helicopsyche giboni Johanson, 1997 and Helicopsyche anomana sp.n. on Madagascar. of Dc, about as long as fork 2 and cell between the two forks; $\mathrm{M}$ and $\mathrm{Cu}_{1}$ apparently fused along their length, except the distal part; the fused veins bear long longitudinal sensilla; slender, plate-like setae scattered in proximal $\mathrm{R}$ and $\mathrm{M}$ sectors; proximal $\mathrm{Cu}_{2}$ runs parallel with wing margin; A-veins apparently absent. Hind wing $3.4 \mathrm{~mm}$; with eight hamuli restricted to short median row; no forks present; $A_{1}$ and $A_{2}$ present. Nygma absent in both wings. Abdomen: sternites without reticulation; sternite VI with large process and runs posteroventrally (fig. 3). Genitalia (figs. 4-8): Segment IX, lateral view, short, dorsally extended into anterior triangular (fig. 4), with anterior margin strengthened (fig. 4); in dorsal and ventral view broadly cleaved. Tergite X, lateral view (fig. 4), large, continuous with segment IX; basally broad and tapers strongly towards median part; distal part hooked upwardly; two lateral setae pairs present on median part (figs. 4 and 5). Superior appendages (fig. 5), tuboid, originate between the Xth tergal branches and run posteriorly, each with two apical setae. Gonocoxite simple, without secondary branch; in lateral view (fig. 4), proximally sub- straight; apex slightly angled dorsally and supports four setae; the basomedian process conspicuous, oriented posteroventrally, and with two apical setae. In ventral view (fig. 6), smoothly curved medially; basomedian processes oriented posteromedially. Basal plate indistinct, but with two anterolateral processes (fig. 6). Phallus (fig. 7): short, strongly curved ventrally, with long processes originating dorsally on basal part (fig. 8) having two apical setae (fig. 8).

\section{Distribution}

The species, represented by a single male, is only recorded from its type locality, at the Sahatandra River in the Rianila Basin, located in the middle part of the eastern coast of Madagascar (Fig. 9). The locality is close to the type locality of the other species, $H$. giboni.

\section{Phylogenetic RELATIONSHIP}

\section{Methods}

A phylogenetic analysis including all Madagascan, Seychellean and eight out of ten East African Heli- 

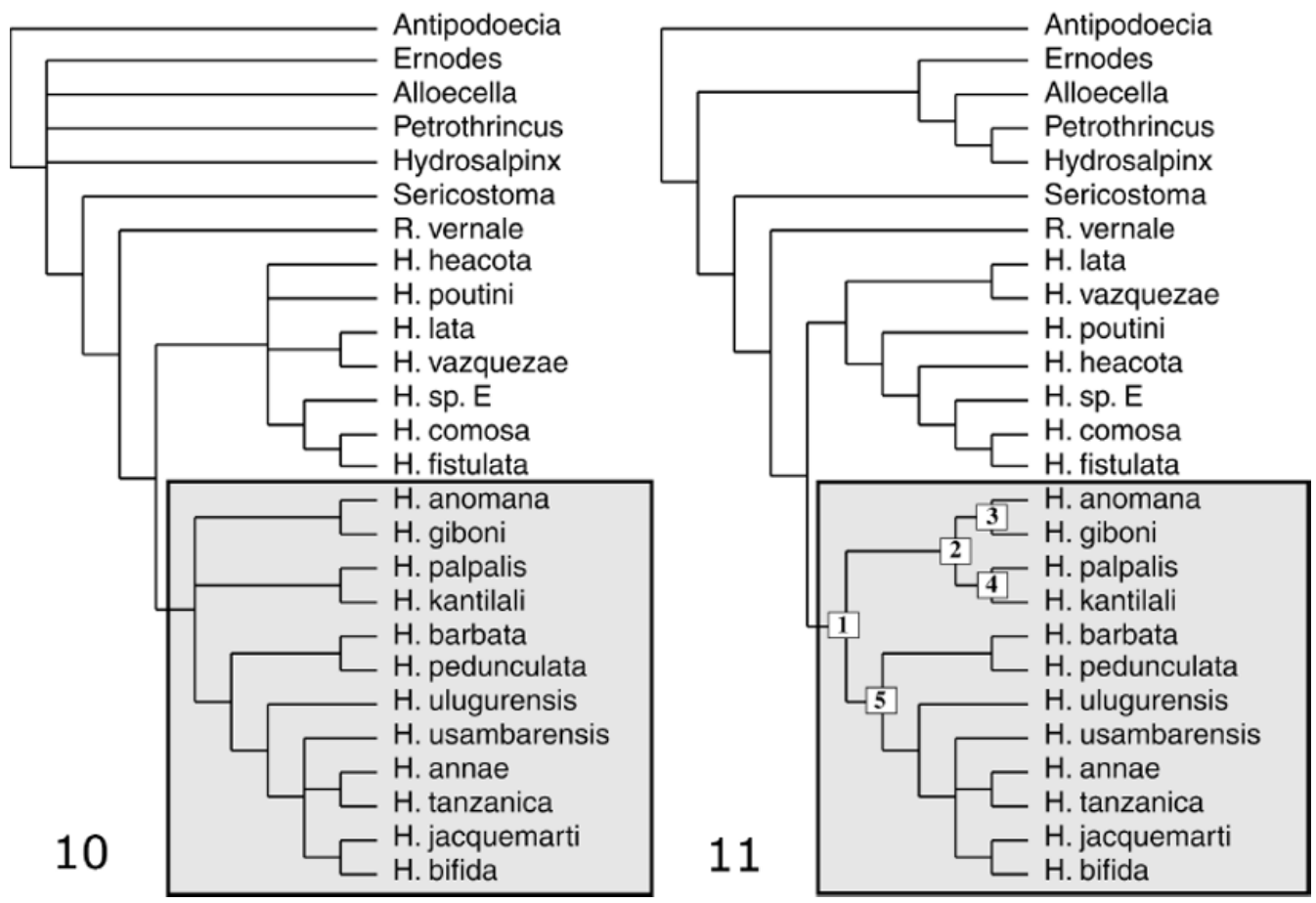

Figs. 10-11. Results of the cladistic analyses. - 10, Strict consensus tree before successive reweighting. Based on 9 shortest trees. The subgenus Petrotrichia is shaded; 11, Strict consensus tree after successive reweighting. Based on 3 shortest trees. The subgenus Petrotrichia is shaded. Node numbers refer to synapomorphy list in Tab. 3 and the text.

copsyche is executed. The following two East African species, $H$. marlieri and $H$. stoltzei, were excluded from the analysis in order to reduce the amount of uncertainties in the data matrix due to lack of other characters but genitalic ones. The outgroup was selected to include basal representatives of related species groups within Helicopsyche, and also the genus Rakiura (Helicopsychidae), as well as representatives of related families by the genera Sericostoma (Sericostomatidae), $H y$ drosalpinx (Hydrosalpingidae), Petrothrincus (Petrothringhidae), Alloecella (Calocidae), Ernodes (Beraeidae) and Antipodoecia (Antipodoeciidae). The characters used and data matrix are presented in tables 1 and 2 , respectively. The data matrix comprises 96 characters of which 18 are multistate characters $(3,18,21$, $29,30,32,45,46,56,60,61,67,70,71,77,80,83$ and 92). All multistate characters, except characters 61, 67 and 92, were treated as linearly ordered. Initially, all characters were equally weighted. PAUP* (Swofford 1998) was used to find most parsimonious trees. Totally 1000 replicate searches were performed with different starting points, and all minimal length trees were retained in each replicate.

To reduce the effects of homoplasious characters in the analysis, a successive reweighting approach (Farris 1969) was performed. A base weight of 1.00 was given non-homoplasious characters, and a similar analysis to the initial one was performed.

\section{Results}

The initial analysis resulted in nine shortest trees within a single island. The strict consensus tree is given in fig. 10 and shows that the subgenus Petrotrichia is monophyletic, as is indicated on grey background. In Petrotrichia, the basal clades were not fully resolved in that the Madagascan, Seychellean and mainland groups formed three distinct monophyletic clades within a trichotomy. This due to two alternative configurations: one which groups the Madagascan species into a basal Petrotrichia clade, or alternatively as a sister group to the Seychellean species clade. After reweighting, three shortest trees were obtained, all identical to a subset of the shortest trees found in the initial analysis. The strict consensus tree based on reweighted characters is given in fig. 11. In this tree, the Madagascan species (node 3 in fig. 11) constitutes a monophyletic group and comes out as the sister group to the Seychellean species (node 4 in fig. 11). 
The result corresponds with that in Johanson (1998), i.e. the species-relationship in the clade comprising the Afrotropical species. This tree is preferred over competing trees as it is based on analysis that downweighted homoplasious characters. The character state transformations for nodes 1-5 in fig. 11 are listed in table 3.

The unambiguous characters supporting the monophyly of the Madagascan species are: presence of a long trichoid setae along forewing $\mathrm{Cu}_{1}+\mathrm{M}$; the forewing $\mathrm{M}$ and $\mathrm{Cu}_{1}$ are almost fused; the segment IX, best seen in lateral view, has its dorsal part anteriorly extended; the genitalia has a basal plate divided into dorsal branches; the gonocoxite is slender and distally angled dorsally; the tergum $\mathrm{X}$ is divided into two widely separated branches and has its distal part dorsally hooked. In addition, several ambiguous characters support the monophyly (see table 3).

The monophyly of the two Seychellean species (node 4 in fig. 11) is supported by the presence of one unambiguous character: the secondary branch of gonocoxite has a strong, apical seta. In addition, the clade is supported by the absence of a fore leg posterior spur (also absent in H. lata and vazquezae); the reduction of the $\mathrm{Cu}_{2}$ (also reduced in Alloecella); the short, wart-like superior appendage (also in $H$. vazquezae); and the secondary reduction of sclerous processes on the phallus (also in $H$. pedunculata).

The clade comprising both the Madagascan and Seychellean species (node 2 in fig. 11) forms a sister group to the mainland species (node 5 in fig. 11). The group of Madagascan and Seychellean species is supported by the presence of a rounded forewing apex, which is the only character that unambiguously supports the monophyly of that clade. Other, ambiguous characters are: the presence of eye ommatrichia (also in Sericostoma); the hindwing breadth over hindwing length ratio is less than 0.22 (secondary modified in anomana); and the absence of abdominal reticulation (also in non-helicopsychids).

\section{Conclusion}

Classifying $H$. anomana together with the other primitive $H$. giboni is supported by several synapomorphies. It is also clear that the Madagascan species form a clade that is the sistergroup to the Seychellean species, which in turn forms a sistergroup to the East African mainland species. Johanson (1998) concluded that the subgenus Petrotrichia is one of the oldest groups within Helicopsychidae. It was probably present in Africa at the time when Africa and South America broke off about 100 MYA. However, ancestral species probably dispersed to the Seychelles and Madagascar from East Africa more recently, probably later than 55 MYA (Johanson 1998: 124). H. anomana can thus be considered as one of the most primitive species within the family Helicopsychidae.

The Helicopsychidae fauna of Madagascar is probably richer than presently observed. And presence of primitive Helicopsychidae clades in this region should entail a stronger focus on that part of the distribution range of the family. Detection of more species would likely add valuable information to a better understanding of Helicopsychidae phylogeny and biogeographical pattern.

\section{REFERENCES}

Farris, J. S., 1969. A successive approximations approach to character weighting. - Systematic Biology 18: 374-385.

Johanson, K. A., 1997. Description of Helicopsyche giboni sp.n. from Madagascar (Trichoptera: Helicopsychidae). Braueria 24: 5-6.

Johanson, K. A., 1998. Phylogenetic and biogeographic analysis of the family Helicopsychidae (Insecta: Trichoptera). - Entomologica scandinavica Supplement 53. 172 pp.

Johanson, K. A. \& E. Willassen, 1997. Are the African species of Helicopsyche von Siebold, 1856 (Insecta: Trichoptera: Helicopsychidae) monophyletic? - Tropical Zoology 10: 117-128.

Marlier, G. \& H. Malicky, 1979. A new Helicopsyche from the Seychelles (Trichoptera, Helicopsychidae). Zeitschrift der Arbeitsgemeinschaft Österreichischer Entomologen 30: 110-112.

Swofford, D. L., 1998. PAUP*. Phylogenetic Analysis Using Parsimony (*and other methods). version 4. - Sinauer, Sunderland, Massachusetts.

Ulmer, G., 1910. Trichoptera. - In: Percy Sladen Trust. Expedition, Indean Ocean in 1905. - Transactions of the Linnean Society of London 3: 41-54.

Received: 29 January 2001

Accepted: 7 June 2001 
Table 1. List of characters used in the cladistic analysis. The character alternatives are scored in the matrix in table 2. "\#" refers to character numbers.

\section{\# Character state description}

1 Maxillary palp proximal joint with medial stout setae absent (0), present (1).

2 Maxillary palp distal joint as long or longer than proximal joint (0), shorter (1).

3 Maxillary palp 5-jointed (0), 3-jointed (1), 2-jointed (2).

4 Frontal tentorial opening with black line absent (0), present (1).

5 Postantennal warts absent (0), present, flat (1), present, tuboid (2), present, tuboid and bifurcated (3), present, associated with cephalic warts (4).

6 Eye ommatrichia absent (0), present (1).

7 Tentorial arm lateral process present (0), absent (1).

8 Tentorial bridge process present (0), absent (1).

9 Fore leg posterior spur as long as anterior spur (0), shorter than anterior spur (1).

10 Fore leg posterior spur present (0), absent (1).

11 Cervical sclerite uniformely pale (0), with strongly pigmented margin (1).

12 Pronotum with setal warts in two pairs (0), one pair (1).

13 Mesonotum postnotal line present (0), absent (1).

14 Mesonotal warts present 0 , absent (1).

15 Forewing length over Dc length more than $4.5 \mathrm{x}(0)$, less than $4.5 \mathrm{x}(1)$.

16 Forewing apex slightly pointed (0), rounded (1).

17 Forewing distance between broadest part to apex over length of broadest part less than $1.2 \mathrm{x}(0)$, more than $1.2 x$ (1) (see fig. 16 in Johanson 1998)

18 Forewing fork 1 originates proximally or medially on discoidal cell (0), on distal half (1), close to or on distal corner (2).

19 Forewing basal $R_{5}$ originates proximally to $R_{3}-R_{4}(0)$, on line or distally (1).

20 Forewing fork 3 present (0), absent (1).

21 Forewing crossvein R-M ends well into $M_{1+2}(0)$, R-M ends on point of bifurcation of $M$ to $M_{1+2}$ and $M_{3+4}$ (1), R-M meets $M$ before bifurcation of $M(2), R_{5}$ tangent to $\mathrm{M}(3)$.

22 Forewing $\mathrm{Cu}_{1 \mathrm{~b}}$ present (0), absent (1).

23 Forewing $\mathrm{Cu}_{2}$ present (0), absent (1).

24 Forewing $A_{1+2}$ meets wing margin at some distance from fork $5(0)$, very close to fork 5 (1).

25 Forewing nygma in fork 2 present (0), absent (1).

26 Forewing nygma in thyridium cell present $(0)$, absent (1).

27 Forewing long trichoid setae along $\mathrm{Cu}_{1}$ absent (0), present (1).

28 Forewing $M_{4}$ sensilla basiconica on $M_{4}$ in number of two (rarely one) (0), absent (1).

29 Hindwing hamuli absent (0), straight, and exceeding $0.37-0.54$ wing length (1), curved, and exceeding 0.37 0.54 wing length $(2)$, curved, exceeding $0.58-0.63$ wing length (3).

30 Hindwing breadth over length less than $0.22(0), 0.24$ 0.38 (1), more than 0.41 (2).

31 Hindwing anterior margin substraight (0), sigmoid (1).

32 Hindwing fork 1 shorter than its stalk, and with proximally oriented $R_{2}(0)$, shorter than its stalk, and with distally oriented $\mathrm{R}_{2}(1)$, longer than its stalk, and with distally oriented $\mathrm{R}_{2}(2)$.

33 Hindwing fork 1 present (0), absent (1).

34 Hindwing Dc present (0), absent (1).

35 Hindwing fork 3 present (0), absent (1).

36 Hindwing $M$ includes more than one vein (0), includes only one vein (1).

37 Hindwing crossvein $\mathrm{M}-\mathrm{Cu}$ present (0), absent (1).

38 Hindwing $\mathrm{Cu}_{1}$ divides into $\mathrm{Cu}_{1 \mathrm{a}}$ and $\mathrm{Cu}_{1 \mathrm{~b}}(0)$, simple (1).

39 Hindwing $\mathrm{Cu}_{2}$ is separate from $\mathrm{Cu}_{1}(0)$, basally fused with $\mathrm{Cu}_{1}(1)$.

40 Hindwing $\mathrm{Cu}_{2}$ present (0), absent (1)

41 Hindwing nygma in fork 2 present (0), absent (1).

42 Forewing $\mathrm{M}$ and $\mathrm{Cu}_{1}$ well separated (0), almost fused and with long setae (1).

43 Tergite I dorsal setose structure absent (0), present (1).

44 Tergites I-VIII anterior margins straight or convex (0), concave (1).

45 Abdomen with sternal reticulation absent (0), present on sternum III only (1), present on sternites II-V (2).

46 Abdominal sternum VI without process (0), with stump process (1), with pointed process (2), with truncated process (3), with tongue shaped process (4).

47 Abdominal sternites without transverse apodeme (0), transverse apodeme present (1).

48 Sternite IX membranous areas absent (0), membranous areas present (1).

49 Sternite IX not extendede or divided (0), extended posteriorly and divided (1).

50 Segment IX with pleural apodeme to k-axis bent downward running anteriorly (0), in right angle to k-axis (1), bent upward running anteriorly (2). (see fig. 26 in Johanson 1998)

51 IXth pleural apodeme present (0), absent (1).

52 Tergum IX dorsally oriented, rounded process absent (0), present (1).

53 Segment IX, lateral view, with dorsal part anteriorly rounded (0), dorsal part anteriorly pointed (1).

54 Superior appendage long and slender (0), short and wart-like (1).

55 Superior appendage base completely sclerotized (0), with membranous area (1).

56 Superior appendage located laterally (0), dorsolaterally (1), dorsally (2).

57 Superior appendage with small, basal process absent (0), present (1)

58 Basal plate undivided (0), divided into dorsal branches (1).

59 Gonocoxite primary branch anterior margin concave (0), straight or convex (1).

60 Gonocoxite simple, with only primary branch present $(0)$, with very short secondary branch (1), with secondary branch about half as long as thr primary branch (2), with secondary branch as long as primary branch (3).

61 Gonocoxite primary branch distally gradually broader and with apex rounded (0), uniformely broad and apex pointed ventrally (1), slender and tapering (2), slender and needle shaped (3), proximal part angled posteriorly and distally parallel with secondary branch (4), short, and directed dorsally (5), uniformely broad, not with pointed apex (6), slender, and angled dorsally (7).

62 Gonocoxal secondary branch median setae present (0), absent (1).

63 Gonocoxal secondary branch apical seta absent (0), a 
single, long seta present (1).

64 Gonocoxal basomedian process absent (0), present (1).

65 Gonocoxal basomedian branch megasetae absent (0), dorsoapical megasetae present on posterior oriented consoloid process (1), apical megasetae on tube-shaped posteriorly oriented process (2).

66 Gonocoxite secondary branch basomedially not produced (0), produced medially (1).

67 Gonocoxite basomedian branch absent (0), present on basal plate, and short (1), present basally on primary branch, and long (2).

68 Gonocoxite primary branch volsella absent (0), present (1).

69 Phallus slightly curved (0), strongly curved ventrally (1).

70 Phallic sclerous process, if present, without microtrichia (0), scattered with microtrichia (1), with microtrichia in crown (2).

71 Phallic sclerous processes absent (0), one pair present (1), two pairs present (2).

72 Tergum X laterally slender (0), laterally broad (1).

73 Tergum X with anterodorsal margin straight or convex (0), hooked dorsally (1).

74 Tergum X ventroapically not enlarged (0), enlarged (1).

75 Tergum X widely divided apically (0), narrowly divided apically (1).

76 Tergum $\mathrm{X}$ with apical division shorter than $1.2 \mathrm{x}$ its segment breadth (0), longer than $1.2 \mathrm{x}$ its segment breadth (1).

77 Tergum $X$ with dorsal setae in number of 2-4, mainly 3 (0), 5-9 (1), more than 9 (2).

78 Tergum X, dorsal view, proximally fused (0), proximally separated (1).

79 Female with process on sternite VI absent (0), present (1), secondarily reduced (2).

80 Female ductus bursa more than $2 x$ longer than spermathecal sclerite (0), between 1-2x length of spermathecal sclerite (1), less than $0.5 x$ length of spermathecal sclerite (2).

81 Female with base of spermathecal gland present medailly on sperm duct (0), distally on sperm duct (1).

82 Female segment IX dorsal part uniformely sclerotized (0), with membranous area (1).

83 Female pleurite IX comb area formed by microtrichia absent (0), present and without cells (1), present and with cells (2).

84 Female segment IX parameres present laterally (0), absent (1).

85 Female segment IX with setae in group (0), no setae in group (1).

86 Fermale tergum IX rounded dorsally (0), tapering dorsally (1).

87 Female segment $\mathrm{X}$ with dorsal branch oriented posteriorly (0), curved ventrally (1).

88 Larval case encloseure perforated (0), with split (1).

89 Larval case uncoiled (0), dextrally coiled (1).

90 Larval antennae originate close to anterior margin of head capsule (0), midway between eye and anterior margin of head capsule (1).

91 Larval head carina absent (0), slightly developed (1), well developed (2)

92 Larvae with pronotal megasetae on anterior margin absent (0), with few lateral megasetae (1), with lateral and median megasetae (2), with median megasetae (3).
93 Larval pronotum postmedian dark spots absent (0), present (1)

94 Larval fore leg femur with two dorsal setae (0), with many setae (1).

95 Larval fore leg femur 1.2-2.0 x longer than its trochanter (0), less than or equally long to its trochanter (1).

96 Larval abdominal gills present (0), absent (1).

Table 3. List of character transformations supporting the monophyly of the clades shown by node number $1-5$ in fig. 11. Character numbers in bold indicate characters with unambiguous character transformations; "Node \#" refers to the node numbers in fig. 11; "Character \#" refers to the character numbers listed in table 1; "ci" refers to the consistency indices for the characters supporting the clades 1-5 in fig 11 ; and "State change" refers to the character state change for each character supporting clades 1-5 in fig. 11 .

Node\# Character\# ci State change

\begin{tabular}{|c|c|c|c|}
\hline \multirow[t]{14}{*}{1} & 15 & 0.200 & $1 \rightarrow 0$ \\
\hline & 22 & 0.333 & $0 \rightarrow 1$ \\
\hline & 32 & 0.400 & $1 \rightarrow 2$ \\
\hline & 37 & 0.500 & $0 \rightarrow 1$ \\
\hline & 38 & 0.333 & $0 \rightarrow 1$ \\
\hline & 51 & 0.333 & $0 \rightarrow 1$ \\
\hline & 56 & 0.500 & $0 \rightarrow 1$ \\
\hline & 62 & 0.500 & $0 \rightarrow 1$ \\
\hline & 71 & 0.286 & $0 \rightarrow 1$ \\
\hline & 76 & 0.333 & $0 \rightarrow 1$ \\
\hline & 79 & 1.000 & $0 \rightarrow 1$ \\
\hline & 80 & 1.000 & $1 \rightarrow 2$ \\
\hline & 85 & 0.200 & $1 \rightarrow 0$ \\
\hline & 95 & 0.500 & $1 \rightarrow 0$ \\
\hline \multirow[t]{5}{*}{2} & 6 & 0.500 & $0 \rightarrow 1$ \\
\hline & 16 & 1.000 & $0 \rightarrow 1$ \\
\hline & 30 & 0.667 & $1 \rightarrow 0$ \\
\hline & 45 & 0.667 & $1 \rightarrow 0$ \\
\hline & 60 & 0.176 & $3 \rightarrow 1$ \\
\hline \multirow[t]{17}{*}{3} & 14 & 0.200 & $1 \rightarrow 0$ \\
\hline & 15 & 0.200 & $0 \rightarrow 1$ \\
\hline & 17 & 0.500 & $0 \rightarrow 1$ \\
\hline & 27 & 1.000 & $0 \rightarrow 1$ \\
\hline & 28 & 0.333 & $0 \rightarrow 1$ \\
\hline & 33 & 0.333 & $0 \rightarrow 1$ \\
\hline & 42 & 1.000 & $0 \rightarrow 1$ \\
\hline & 53 & 1.000 & $0 \rightarrow 1$ \\
\hline & 56 & 0.500 & $1 \rightarrow 2$ \\
\hline & 58 & 1.000 & $0 \rightarrow 1$ \\
\hline & 60 & 0.176 & $1 \rightarrow 0$ \\
\hline & 61 & 1.000 & $0 \rightarrow 7$ \\
\hline & 62 & 0.500 & $1 \rightarrow 0$ \\
\hline & 73 & 1.000 & $0 \rightarrow 1$ \\
\hline & 77 & 0.400 & $1 \rightarrow 0$ \\
\hline & 78 & 1.000 & $0 \rightarrow 1$ \\
\hline & 85 & 0.200 & $0 \rightarrow 1$ \\
\hline \multirow[t]{5}{*}{4} & 10 & 0.500 & $0 \rightarrow 1$ \\
\hline & 40 & 0.500 & $0 \rightarrow 1$ \\
\hline & 54 & 0.500 & $0 \rightarrow 1$ \\
\hline & 63 & 1.000 & $0 \rightarrow 1$ \\
\hline & 71 & 0.286 & $1 \rightarrow 0$ \\
\hline \multirow[t]{3}{*}{5} & 24 & 0.500 & $0 \rightarrow 1$ \\
\hline & 71 & 0.286 & $1 \rightarrow 2$ \\
\hline & 92 & 1.000 & $0 \rightarrow 3$ \\
\hline
\end{tabular}




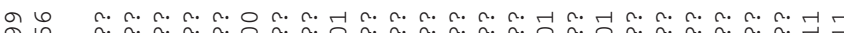

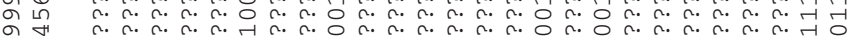

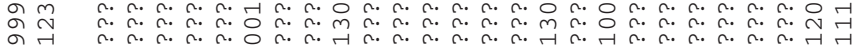

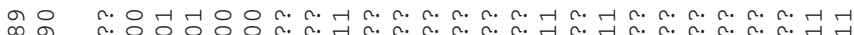

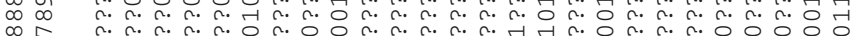

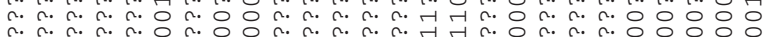
n. n. n. n. n. $n$. n. n. n. n. n. n $n$ 人.

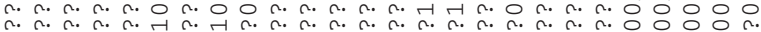

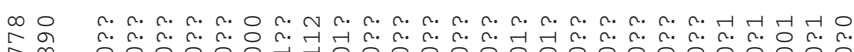

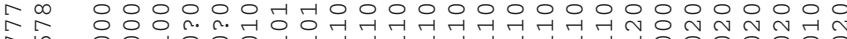

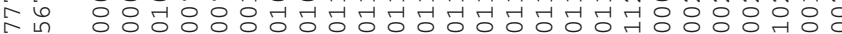

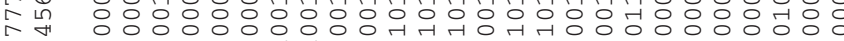
세

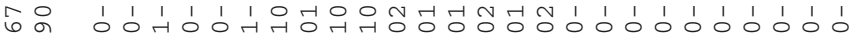

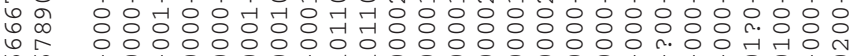

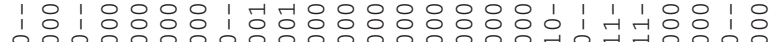
1,0100000010000000

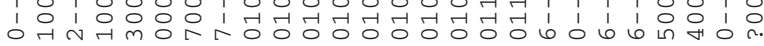

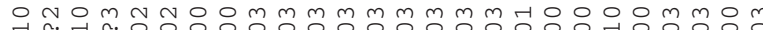
出

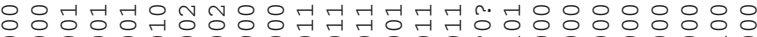

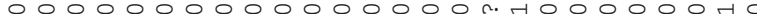
Lก

$\stackrel{10}{\forall}$ 은

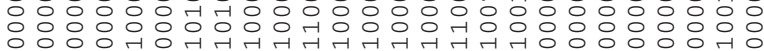

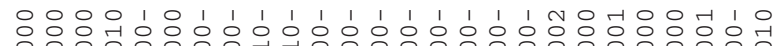

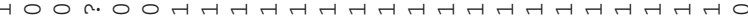

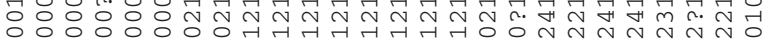

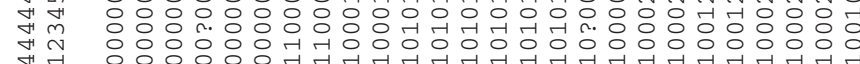

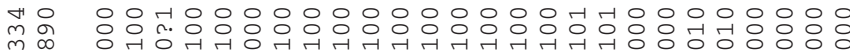
m

$m$

$m \stackrel{m}{m}$

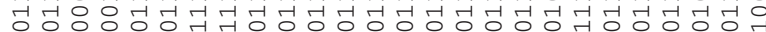

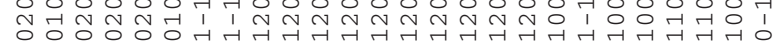

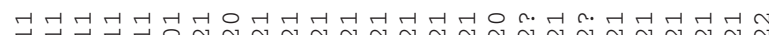
Nָ N

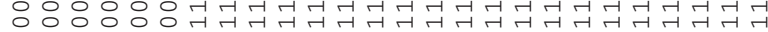

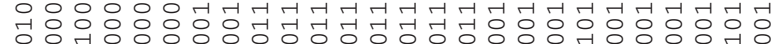
$\stackrel{\sim}{\sim}$

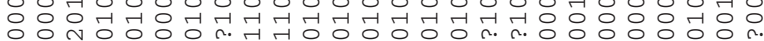

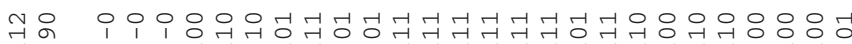
거일 거의

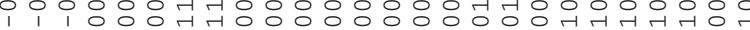

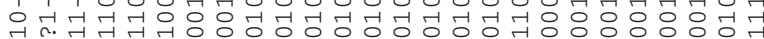

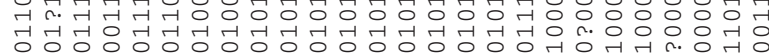

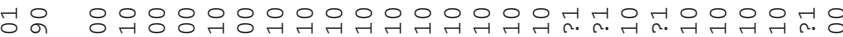

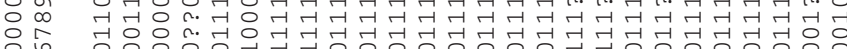

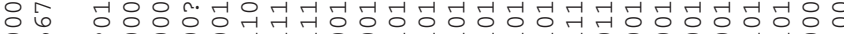

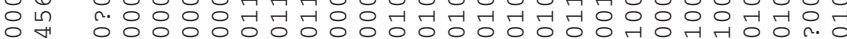

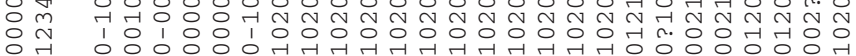

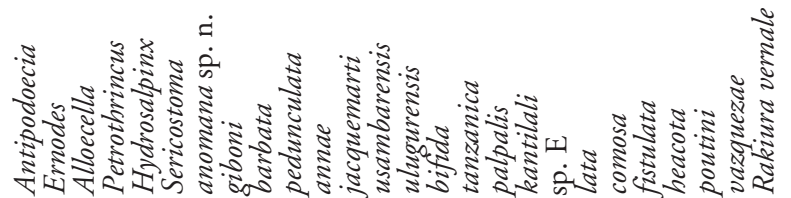

